\title{
THE INFLUENCE OF THE SHIP'S SPEED AND DISTANCE TO AN ARBITRARILY SHAPED BANK ON BANK EFFECTS
}

\author{
Evert Lataire \\ Maritime Technology Division, \\ Ghent University \\ Ghent, Belgium
}

\author{
Marc Vantorre \\ Maritime Technology Division, \\ Ghent University \\ Ghent, Belgium
}

\author{
Guillaume Delefortrie \\ Flanders Hydraulics Research, \\ Antwerp, Belgium
}

\begin{abstract}
A displacement vessel - obviously - displaces a (large) amount of water. In open and deep navigation areas this water can travel almost without any restriction underneath and along the ship's hull. In restricted and shallow waterways, however, the displaced water is squeezed under and along the hull. These bathymetric restrictions result in increased velocities of the return flow along the hull. The resulting pressure distribution on the hull causes a combination of forces and moments on the vessel. If generated because of asymmetric flow due to the presence of a bank, this combination of forces and moment is known as bank effects.
\end{abstract}

By far the most comprehensive and systematic experimental research program on bank effects has been carried out in the Towing Tank for Manoeuvres in Shallow Water (cooperation Flanders Hydraulics Research - Ghent University) at Flanders Hydraulics Research (FHR) in Antwerp, Belgium. The obtained data set on bank effects consists of more than 14000 unique model test setups. Different ship models have been tested in a broad range of draft to water depth ratios, forward speeds and propeller actions. The tests were carried out along several bank geometries at different lateral positions between the ship and the installed bank.

The output consists of forces and moments on hull, rudder and propeller as well as vertical ship motions. An analysis of this extensive database has led to an increased insight into the parameters which are relevant for bank effects.

Two important parameters are linked to the relative distance between ship and bank and the ship's forward speed. The relative position and distance between a ship and an arbitrarily shaped bank is ambiguous. Therefore a definition for a dimensionless distance to the bank will be introduced. In this way the properties of a random cross section are taken into account without exaggerating the bathymetry at a distance far away from the ship or without underestimating the bank shape at close proximity to the ship.
The dimensionless velocity, named the Tuck number $(\mathrm{Tu})$, considers the water depth and blockage, and is based on the velocity relative to the critical speed. The latter is dependent on the cross section (and thus the bank geometry) of the waterway.

\section{INTRODUCTION}

The main dimensions of ships have increased dramatically over the last decades. Unfortunately, it is not feasible to have the natural rivers or manmade canals increased at the same rate as the ship dimensions. Therefore vessels sail more often in more restricted and confined waters. Ship behaviour is affected by shallow water hydrodynamics in different ways. Overall the magnitude of the hydrodynamic forces will increase with decreasing under keel clearance.

Bank effects can be defined as the hydrodynamic influence of the presence of banks on a sailing vessel. This influence manifests itself on the vessel in various ways and can be split, for better understanding, into different sub-effects. Forces act on the vessel in lateral, longitudinal and vertical direction, causing attraction or repulsion from the bank, increased resistance and running sinkage, respectively; also moments are induced resulting in a different trim (pitch moment), heading (yaw moment) and heel angle (roll moment). Bank effects can be defined as the hydrodynamic (quasi) stationary reactions on a vessel caused by a boundary or structure which is approximately parallel to a vessel's course. These effects need to be implemented into ship manoeuvring simulators to obtain a realistic ship behaviour in confined waters. Therefore, a mathematical model is required which outputs the ship-bank interaction forces in an accurate and reliable way, and which is able to cope with arbitrary cross section geometries and ship types. 


\section{BANK EFFECTS}

The fundamental principle of bank effects acts as follows: A moving displacement vessel displaces an amount of water and this amount of displaced water travels along the hull. For a vessel sailing ahead this water runs from the bow towards the stern. On wide and open shipping routes (ocean) this water can travel almost without restrictions along and under the vessel. This water flow induces some hydrodynamic phenomena (squat among others) but no bank effects.
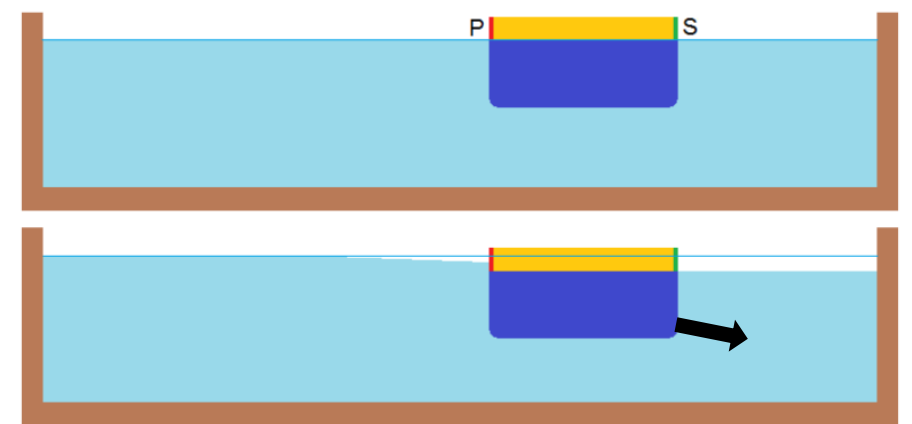

Figure 1 a schematic cross section of a vessel in a rectangular fairway (port side $(P)$ to the left, starboard side (S) to the right), at rest (above) and with forward speed (below)

In restricted waters the streamlines (Figure 2) around the ship tighten. Now assume a vessel sailing on the starboard side in a fairway with a rectangular cross section as depicted in Figure 1. Similar as sailing on the ocean all the displaced water must travel along the vessel. Actually this is only true as long as the vessel sails at a forward speed smaller than the critical speed, so that there is no presence of solitons and the conservation of mass over the cross section still stands. In the situation as in Figure 1 there is a restriction for the water at the port and starboard sides due to the presence of the banks, and under the vessel between the keel of the ship and the bottom of the fairway.

More water travels along port compared to starboard side because of the smaller free section area at this starboard side. At both sides the water is squeezed in and accelerated (because of the presence of the ship) but relatively more at starboard than at port. To be able to evacuate the necessary amount of water the water velocity will be higher at the more confined starboard side than at the wider port side. For a given forward speed of the vessel, the increase of water velocity will depend on the space available. The more room (in this example at port side), the lower the return speed will be. In this situation there is a speed difference between the port and starboard side of the vessel. In present example the return speed will be higher at the starboard side than at the port side.

The increased water flow between ship and wall will induce a decreased pressure in the same area, the free surface level will drop (Figure 2) in agreement to this pressure drop because the pressure at the free surface must be equal to the atmospheric pressure (as a consequence the hydrostatic pressure must decrease). According to the Bernoulli principle, the velocity difference between the return flows at port and starboard will introduce a pressure difference on the vessel hull. The higher the return speed, the lower the pressure. The pressure at the more restricted starboard side will be lower than at the port side. This pressure difference results in a force and moment acting on the vessel (black arrow in Figure 1).

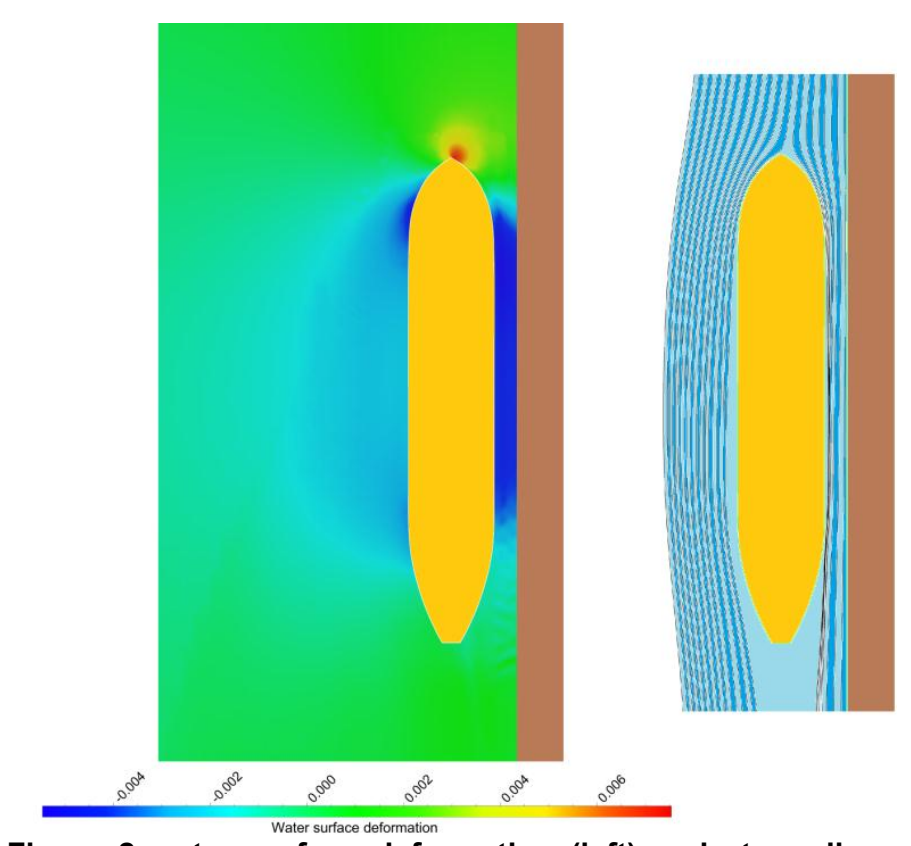

Figure 2 water surface deformation (left) and streamlines (right) of a ship (TOZ) sailing close to a vertical bank

Not always but very commonly (as in previous example) the vessel will endure an attraction force directed towards the closest bank and a yaw moment pushing the bow away from the closest bank. Therefore bank effects are sometimes referred to as bank suction. However, in some specific situations the vessel is pushed away from the closest bank and therefore the term bank effects is favoured.

The influence of the proximity of a bank on the forces parallel to the free surface can be decomposed in different ways. The most common way is splitting the horizontal effects into a lateral force $\mathrm{Y}_{\mathrm{BANK}}$ (acting in the predefined origin of the ship bound coordinate system), a yaw moment $\mathrm{N}_{\text {BANK }}$ (around the vertical axis $\mathrm{z}$ of the same coordinate system) and a longitudinal force $\mathrm{X}_{\mathrm{BANK}}$.

Within this paper, the lateral force and yaw moment are decomposed in a different way (Figure 3):

- a lateral force acting at the forward perpendicular $\mathrm{Y}_{\mathrm{F} \text { BANK} \text {, }}$ denoted $\mathrm{Y}_{\mathrm{F}}$ in this paper for reasons of simplicity;

- a lateral force acting on the aft perpendicular $\mathrm{Y}_{\mathrm{A} \text { BANK, }}$ referred to as $\mathrm{Y}_{\mathrm{A}}$ in this paper.

With:

$$
\begin{aligned}
& Y_{A}=\frac{1}{2} Y_{B A N K}-\frac{1}{L p p} N_{B A N K} \\
& Y_{F}=\frac{1}{2} Y_{B A N K}+\frac{1}{L p p} N_{B A N K}
\end{aligned}
$$




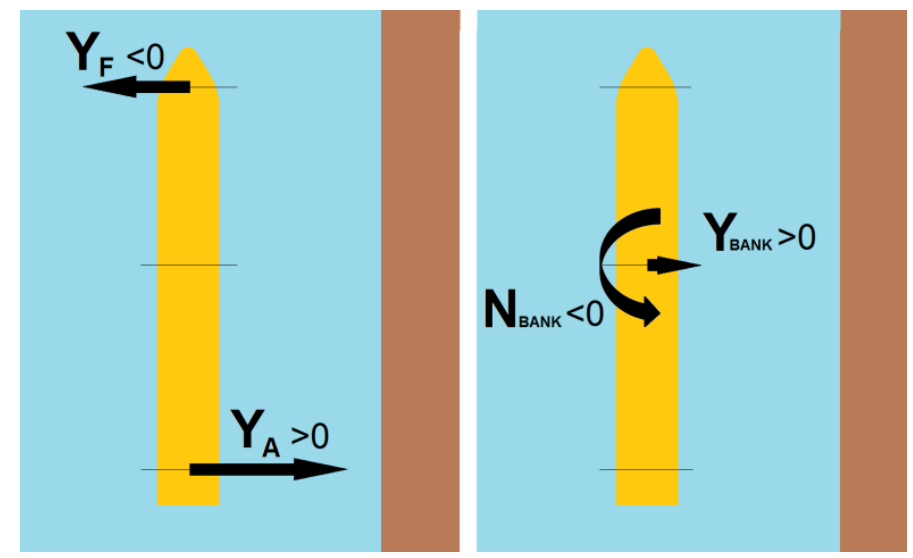

Figure 3 the decomposition of the lateral horizontal bank effect forces

\section{MODEL TESTS}

As bank effects are considered to be a decisive factor for the admittance policy for large, deep-drafted ships to ports making use of confined access channels, a research project on the topic was initiated by the administration of the Flemish Government (Belgium). In 2006-2007 about 12000 systematic model tests were carried out with two ship models and 8 different bank geometries in the Towing Tank for Manoeuvres in Shallow Water (cooperation Flanders Hydraulics Research - Ghent University) in Antwerp, Belgium. In 2010 this systematic series was extended with more than 2000 model tests with 5 different ship models and 4 surface piercing bank geometries. A limited selection of model tests is made public as benchmark data in (Lataire et al. 2009).

A technical overview of this fully automated towing tank can be found in (Van Kerkhove et al. 2009); its main dimensions are listed in Table 1.

\begin{tabular}{|l|r|l|}
\hline length over all & 87.5 & $\mathrm{~m}$ \\
\hline useful length & 68.0 & $\mathrm{~m}$ \\
\hline width & 7.0 & $\mathrm{~m}$ \\
\hline max. water depth & 0.5 & $\mathrm{~m}$ \\
\hline
\end{tabular}

Table 1 the main dimensions of the towing tank at FHR

An overview of the ship models which were tested in the frame of the bank effects research project is given in Table 2. For the Belgian ports of Antwerp and Zeebrugge container carriers are responsible for the largest part of traffic. Therefore two ship models of container carriers have been used. Ship models COU and COP represent single screw container carriers with a capacity of 8000 and 12000 TEU, respectively, the latter having the maximum main dimensions that can call the new Panama locks. The selected drafts are either design values or drafts which at the time of the experiments used to be typical for tide-independent traffic to the port of Antwerp (now increased to $13.1 \mathrm{~m})$.

A ship model (G0M) of the Belgian built $135000 \mathrm{~m}^{3}$ LNGtanker Methania has also been tested along a wide range of bank geometries. The model has been tested at maximum draft only, since this is the more critical situation (smallest under keel clearance and relatively dangerous cargo).

The ship model TOZ has the lines of the openly available KVLCC2 Kriso Tanker (Stern \& Agdrup 2008) and is of high value for comparing towing tank results worldwide and for validating CFD calculations in shallow water (Zou \& Larsson 2013).

Ship model A01, a model of a twin screw RORO ship, has been added to the program for its specific lines and twin screw propulsion system. With respect to bank effects, this implies that an active propeller is located relatively close to the bank compared to a single screw propulsion system.

Model tests have also been carried out with an inland vessel (B01) to provide the full bridge inland simulator at FHR with dedicated mathematical models (in this specific case for bank effects). This model is based on the CEMT (Conférence Européenne des Ministres de Transport) Class Va.

The final model used in present research on bank effects is a so-called Wigley hull (W01), which is not a scaled ship but a mathematically defined geometry with equation:

$$
|y|= \begin{cases}B \frac{z}{T}\left(2-\frac{z}{T}\right) \frac{4 x}{L}\left(1-\frac{x}{L}\right) & z<T \\ B \frac{4 x}{L}\left(1-\frac{x}{L}\right) & z \geq T\end{cases}
$$

Hydrostatic properties and the linesplan can be calculated analytically or with dedicated software. A Wigley hull is a popular and easy to mesh hull form for numerical calculations.

\begin{tabular}{|c|c|c|c|c|c|c|}
\cline { 2 - 7 } \multicolumn{1}{c|}{} & \multicolumn{1}{c}{ LPP $_{\text {PP }}$} & $\mathbf{B}$ & $\mathbf{T}_{\mathbf{F}}$ & $\mathbf{T}_{\mathbf{A}}$ & $\mathbf{C}_{\mathbf{b}}$ & scale \\
\cline { 2 - 7 } \multicolumn{1}{c|}{} & {$[\mathrm{m}]$} & {$[\mathrm{m}]$} & {$[\mathrm{m}]$} & {$[\mathrm{m}]$} & {[]} & {[]} \\
\hline A01 & 190.0 & 31.0 & 7.4 & 7.4 & 0.62 & 50.0 \\
\hline B01 & 108.0 & 11.5 & 3.7 & 3.7 & 0.91 & 25.0 \\
\hline C0P & 348.0 & 48.8 & 15.2 & 15.2 & 0.65 & 80.0 \\
\hline C0U & 331.3 & 42.8 & 12.0 & 12.0 & 0.64 & 80.8 \\
\hline C0U & 331.3 & 42.8 & 14.5 & 14.5 & 0.66 & 80.8 \\
\hline C0U & 331.3 & 42.8 & 13.0 & 14.5 & 0.62 & 80.8 \\
\hline G0M & 266.6 & 41.6 & 11.0 & 11.0 & 0.77 & 70.0 \\
\hline T0Z & 320.0 & 58.0 & 20.8 & 20.8 & 0.81 & 75.0 \\
\hline W01 & 4.00 & 0.40 & 0.25 & 0.25 & 0.44 & 1.0 \\
\hline
\end{tabular}

Table 2 Main dimensions ships tested at full scale, Italic written drafts are design drafts

Different banks have been installed in the towing tank to investigate the influence of the bank geometry on the forces and moments induced on the vessel. Only tests in a steady state regime condition are considered. Therefore the installed bank did not change in geometry for a significant amount of ship lengths (at least six ship lengths) before the ship model decelerates or another bank geometry starts. In case more geometries are installed consecutively in the tank, the transition zone of one bank to another is constructed in such a way to create a smooth change in geometry. This is to avoid abrupt and long lasting transition effects. 
Three types of installed banks can be distinguished in present (and other published) research:

1. A vertical quay wall QY: a surface-piercing vertical wall is mounted on the towing tank bottom, or the walls of the tank itself are used.

\begin{tabular}{|c|c|c|c|}
\hline Name & run/rise & $\mathbf{W}_{\mathbf{h}}$ & $\begin{array}{c}\text { Opposite bank } \\
\text { run/rise }\end{array}$ \\
\hline[] & {[]} & {$[\mathrm{m}]$} & {[]} \\
\hline QY_0_0.812_0 & 0 & 0.812 & 0 \\
\hline QY_0_0.966_0 & 0 & 0.966 & 0 \\
\hline QY_0_1.314_0 & 0 & 1.314 & 0 \\
\hline QY_0_1.933_0 & 0 & 1.933 & 0 \\
\hline QY_0_3.865_0 & 0 & 3.865 & 0 \\
\hline QY_0_4.400_4 & 0 & 4.400 & 4 \\
\hline QY_0_6.330_0 & 0 & 6.330 & 0 \\
\hline QY_0_7.00_0 & 0 & 7.00 & 0 \\
\hline
\end{tabular}

Table 3 Naming and dimensions of the vertical quay walls tested at FHR

2. A surface piercing wall SP: a sloped bank runs at a constant slope from the bottom of the towing tank up to highest water level tested. This slope is expressed as the ratio between the rise and run with a normalised rise (Figure 4).

\begin{tabular}{|c|c|c|c|}
\hline Name & run/rise & $\mathbf{W}_{\mathbf{h}}$ & $\begin{array}{c}\text { Opposite bank } \\
\text { run/rise }\end{array}$ \\
\hline[] & {[]} & {$[\mathrm{m}]$} & {[]} \\
\hline SP_1_4.200_3 & 1 & 4.200 & 3 \\
\hline SP_3_4.200_1 & 3 & 4.200 & 1 \\
\hline SP_3_5.730_0 & 3 & 5.730 & 0 \\
\hline SP_4_4.400_0 & 4 & 4.400 & 0 \\
\hline SP_5_4.030_0 & 5 & 4.030 & 0 \\
\hline SP_8_4.030_0 & 8 & 4.030 & 0 \\
\hline
\end{tabular}

Table 4 Naming and dimensions of the sloped banks as tested at FHR

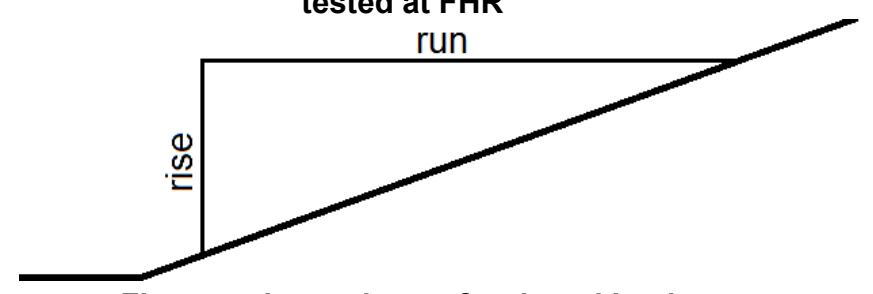

Figure 4 rise and run of a sloped bank

3. A semi submerged bank SS: a sloped bank starts at the bottom of the towing tank but ends before the free surface is reached. A horizontal (submerged) plane connects the slope with the wall of the towing tank or an installed vertical quay wall (Figure 5).

$$
\mathrm{W}_{\max }
$$

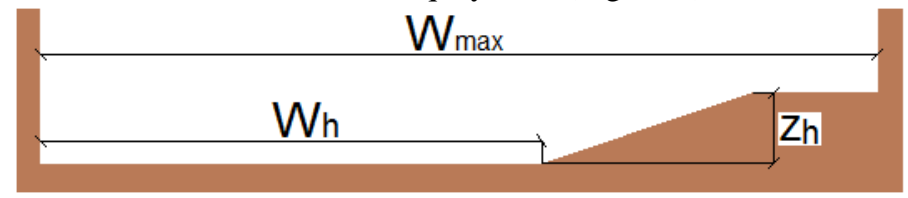

Figure 5 semi submerged bank properties $W_{\max }, W_{h}$ and $z_{h}$

\begin{tabular}{|c|c|c|c|c|}
\hline Name & run/rise & $\mathbf{W}_{\mathbf{h}}$ & $\mathbf{z}_{\mathbf{h}}$ & $\mathbf{W}_{\max }$ \\
\hline[] & {$[\mathrm{m} / \mathrm{m}]$} & {$[\mathrm{m}]$} & {$[\mathrm{m}]$} & {$[\mathrm{m}]$} \\
\hline SS_0_33.00_.245_33.45 & 0 & 33.00 & 0.245 & 33.45 \\
\hline SS_0_33.00_.305_33.45 & 0 & 33.00 & 0.305 & 33.45 \\
\hline SS_0_33.00_.305_39.00 & 0 & 33.00 & 0.305 & 39.00 \\
\hline SS_5_4.030_.120_7.00 & 5 & 4.030 & 0.120 & 7.00 \\
\hline SS_5_4.030_.150_5.335 & 5 & 4.030 & 0.150 & 5.335 \\
\hline SS_5_4.030_.150_5.890 & 5 & 4.030 & 0.150 & 5.890 \\
\hline SS_5_4.030_.150_7.00 & 5 & 4.030 & 0.150 & 7.00 \\
\hline SS_8_4.030_.150_7.00 & 8 & 4.030 & 0.150 & 7.00 \\
\hline
\end{tabular}

Table 5 geometric dimensions of the semi submerged banks

In Figure 6 all water depth (h) to draft (T) ratios are listed with the number of model tests carried out for each ratio. The water depth is defined as the deepest water depth in the cross section and does not change when the ship sails above a sloped bank.

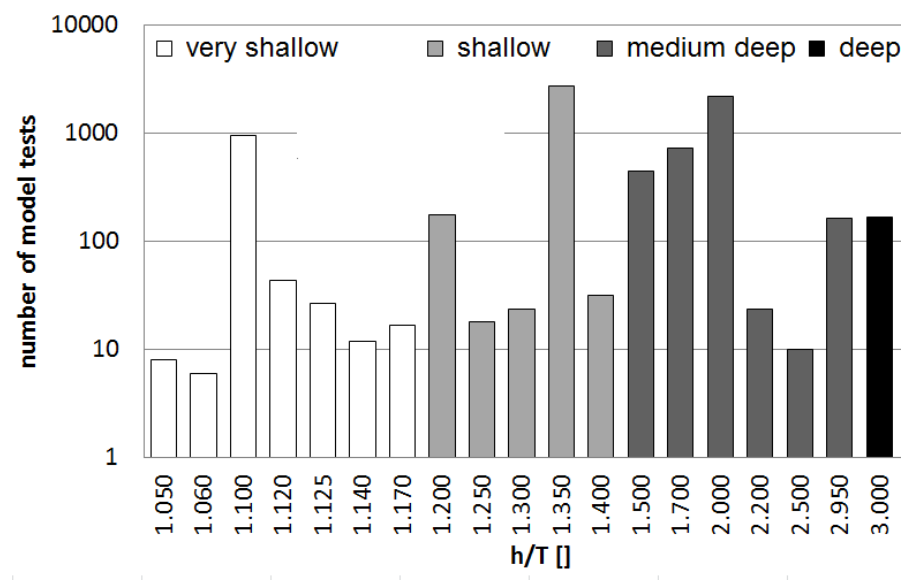

Figure 6 the number of model tests for each $h / T$ ratio

Most of the ship models are tested in 2 to 4 different water depths. In this way, the range of water depths encountered by a seagoing deep drafted vessel approaching or leaving the Flemish harbours is covered. The LNG tanker, for example, is tested at a water depth of 1.35 and 1.70 times the vessels draft which corresponds to the present practice at the harbour of Zeebrugge. The Ro-Ro ship A01, on the other hand, is tested in as much as 14 different water depths varying from 1.10 (very shallow) up to 2.20 (medium deep water) times the draft of the ship model.

The lateral position of a ship model in a towing tank with banks installed can be defined in different ways. The most straightforward method is by referring to the earth bound coordinate system of the towing tank itself. About five lateral positions are tested for all ship-bank-water depth combinations.

In very shallow water most ship models are tested at 6,8 and 10 knots full scale. In shallow water, tests at 12 knots are added and 6 knots excluded. In medium and deep water, velocities corresponding to full scale velocities of 14 and 16 knots are also added to the program. 
The number of velocities can be plotted to the dimensionless Froude Number based on the water depth:

$$
F r_{h}=\frac{V}{\sqrt{g h}}
$$

$h$ being the deepest water depth over the entire cross section, as in Figure 6. In case of a sloping bank, the lateral position of the ship model will therefore not change the corresponding $\mathrm{Fr}_{\mathrm{h}}$. Figure 7 displays the distribution of the number of tests over the $\mathrm{Fr}_{\mathrm{h}}$ range.

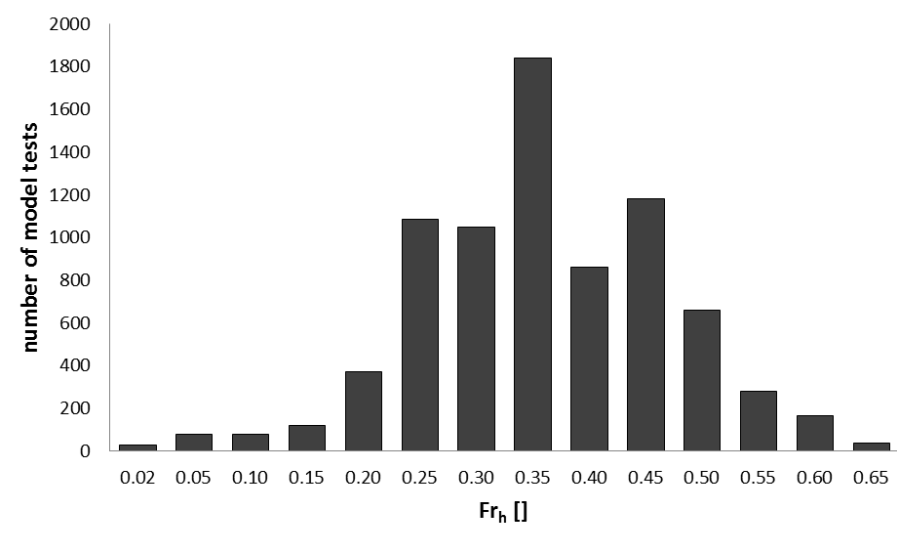

Figure 7 the number of model tests for each $\mathrm{Fr}_{\mathrm{h}}$

The ship models COU, COP, G0M, T0Z and B01 are equipped with one propeller and the ship model A01 with two propellers. During the test runs, the propeller rate was kept constant at a predefined value between zero and $80 \%$ of the maximum rpm for that vessel.

During captive manoeuvring tests, the ship model follows a predetermined trajectory applied by the towing carriage. The ship model is free to heave and pitch but is rigidly connected to the planar motion mechanism according to the other degrees of freedom. The forces acting on the ship model, the rudder and the propeller are measured as well as vertical position of the hull (sinkage), the propeller rate and the rudder angle. Other signals are sampled as well, e.g. wave gauges mounted at a fixed location in the tank.

\section{DISTANCE TO BANK}

It is more seldom than common for a vessel to sail in a rectangular cross section. Sloped banks, dredged channels, natural river bottoms with a varying bathymetry are much more common (Figure 8). As mentioned before, in these types of arbitrary cross sections the lateral position in the fairway is ambiguously defined.

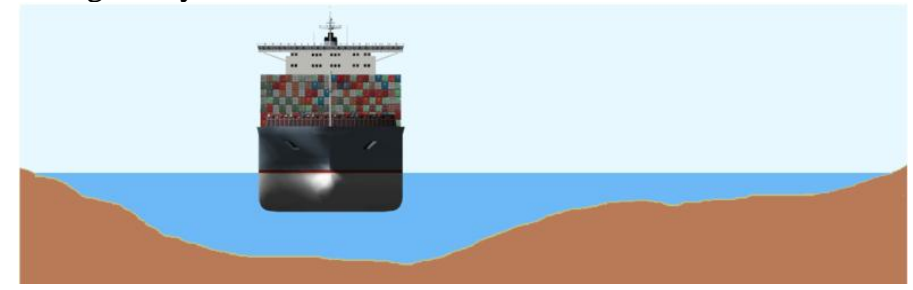

Figure 8 a ship in a arbitrarily shaped cross section
A new expression to include the influence of the lateral position in the mathematical model must cope with all the influences exerted by the elements of an arbitrary bank:

- The further away from the vessel the smaller the influence of the geometry. There is no or almost no influence due to bank elements at a distance far away from the vessel.

- No or almost no influence of the bathymetry should be observed at a depth much deeper than multiple times the draft.

- All types of geometries must be covered. (sloped banks, semi-submerged banks, changing slope angles, random bank geometries such as natural riverbeds, dredged channels, dredged fairway at sea...)

The position and distance between a ship and random shaped bank is ambiguous. Therefore, a non-dimensional parameter $\mathrm{d} 2 \mathrm{~b}$ (distance to bank), based on a weight factor, was introduced by Lataire \& Vantorre (2008). The weight factor w) is a value between 0 and 1 which indicates the influence of a water particle on the bank effects on a ship. A water particle closer to the hull will have a value closer to 1 . The weight factor will tend to zero once the water particle is far away from the ship. The closer the water particle located to the free surface, the larger the weight factor of the water particle. The weight factor of a water particle decreases with the distance from the vessel and the deeper under water. By definition at the cross section of the centre line of the ship and the free surface (at rest) the weight factor is 1 . The weight factor is graphically shown in Figure 9.

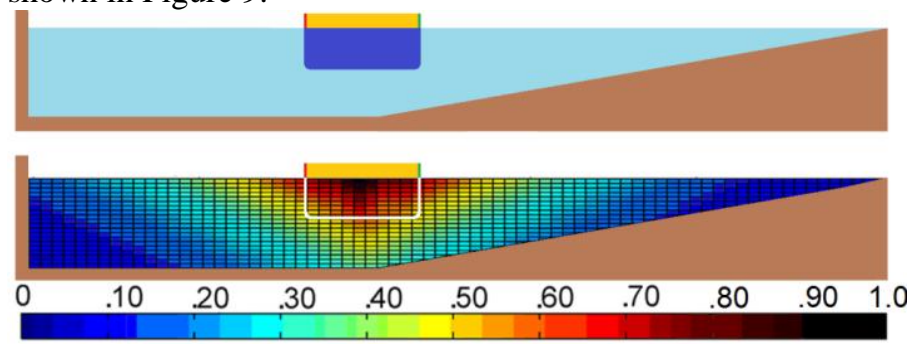

Figure 9 the ship in a cross section and a graphical representation of the weight distribution in the same cross section

The weight factor $\mathrm{w}$ is a decreasing exponential function, analogous to Norrbin's factor (Norrbin 1974). The expression of the weight distribution in the ship bound coordinate system is:

$$
w=e^{-\left(\xi_{y} \frac{|y|}{y_{\text {infl }}}+\xi_{z} \frac{|z|}{T}\right)}
$$

The influence distance $y_{\text {infl }}$ can be described as the boundary between open and confined water. If the ship-bank distance exceeds this value, no (significant) influence of the bank on the forces and moments on the ship will be observed (Lataire \& Vantorre 2008).

The integration of the cross section at both sides of the vessel can be calculated with equations (6) and (7). Here the weight factor can be seen as a (ship dependent) overlay sheet 
which is placed on the cross section under consideration. All 'water particles' are taken into account, also the particles at a distance far away from the vessel but the weight value for these particles will be insignificantly small.

$$
\begin{aligned}
& \chi_{s}=\int_{0}^{h} \int_{0}^{y_{s}} e^{-\left(\xi_{y} \frac{|y|}{y_{\text {infl }}}+\xi_{z} \frac{|z|}{T}\right)} d y d z \\
& \chi_{p}=\int_{0}^{h} \int_{0}^{y_{p}} e^{-\left(\xi_{y} \frac{|y|}{y_{\text {infl }}}+\xi_{z} \frac{|z|}{T}\right)} d y d z
\end{aligned}
$$
10.

A graphical interpretation of $\chi_{p}$ and $\chi_{s}$ is shown in Figure

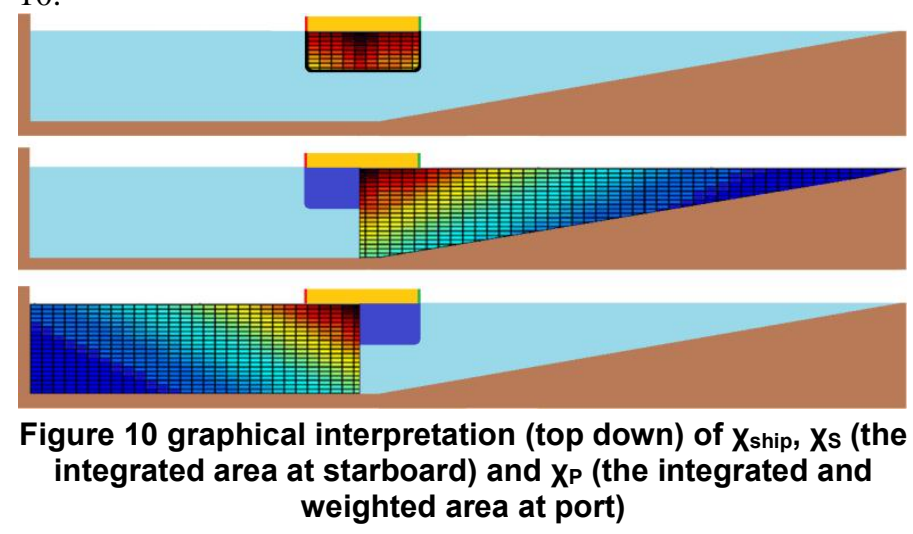

The dimensionless distance to bank parameter $\mathrm{d} 2 \mathrm{~b}$ is by definition:

$$
\frac{1}{d 2 b}=d 2 b^{-1}=\frac{\frac{\chi_{s h i p}}{2}}{\chi_{s}}-\frac{\frac{\chi_{s h i p}}{2}}{\chi_{p}}=\frac{\chi_{\text {ship }}}{2 \chi_{s}}-\frac{\chi_{\text {ship }}}{2 \chi_{p}}
$$

The purpose of the introduction of $d 2 b^{-1}$ is to obtain a parameter to which the forces $\mathrm{Y}_{\mathrm{A}}$ and $\mathrm{Y}_{\mathrm{F}}$ are proportional:

$$
\begin{aligned}
& Y_{A} \propto d 2 b^{-1} \\
& Y_{F} \propto d 2 b^{-1}
\end{aligned}
$$

The values of coefficients $\xi_{\mathrm{y}}$ and $\xi_{\mathrm{z}}$. occurring in Equations (6) and (7) have been determined with the regression program "R" (Venables et al. 2002) making use of the model tests results. Both coefficients are constant for each ship-draft combination.

When sailing on the centre line of a symmetric cross section, $\chi_{\mathrm{s}}$ will be equal to $\chi_{\mathrm{p}}$ and thus $\mathrm{d} 2 \mathrm{~b}^{-1}$ will be zero. When sailing in unrestricted waters the values $\chi_{\mathrm{s}}$ and $\chi_{\mathrm{p}}$ again will be equal and as a consequence $\mathrm{d} 2 \mathrm{~b}^{-1}=0$.

The lateral force at the aft perpendicular $\mathrm{Y}_{\mathrm{A}}$ of ship model T0Z is plotted in Figure 11. This plot contains results of model tests carried out at a forward speed according to 10 knots full scale, a water depth of $150 \%$ of the draft and a constant propeller rate $554 \mathrm{rpm}$ (model scale). Six different bank geometries - three vertical banks and three surface piercing banks - are included, with four different lateral positions y for each bank. Similar plots have been obtained for all ship models and under keel clearances investigated.

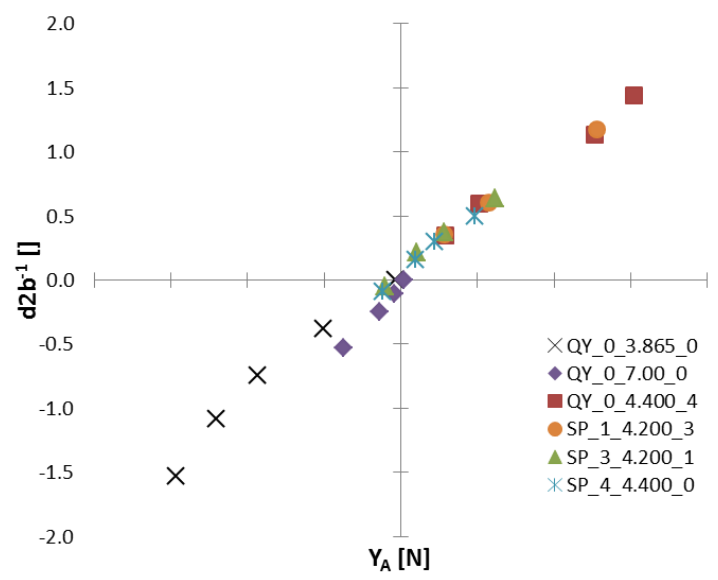

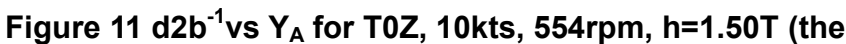
horizontal axis is intentionally left blank for reasons of confidentiality. The origin $(0,0)$ lies on the intersection of both axes).

\section{TUCK NUMBER}

A method to implement the influence of the forward speed of the vessel, the water depth and characteristics of the propeller action in the mathematical model for the lateral forces is sought for.

In (Tuck 1966) a non-dimensional parameter was introduced, which will be referred to as the Tuck number, (Tu) in this paper (Figure 12):

$$
\boldsymbol{T u}(V)=\frac{F r_{h}{ }^{2}}{\sqrt{\left|1-F r_{h}{ }^{2}\right|}}
$$

This dimensionless number increases rapidly when a vessel sails at a velocity $\mathrm{V}$ closer to the critical speed in open water $\left(\mathrm{Fr}_{\mathrm{h}}=1\right)$. The forward velocity of the ship $\mathrm{V}$ is made dimensionless by dividing through the critical velocity in open water $\sqrt{\text { gh }}$. This ratio is the water depth dependent Froude number $\mathrm{Fr}_{\mathrm{h}}$ (equation (4)).

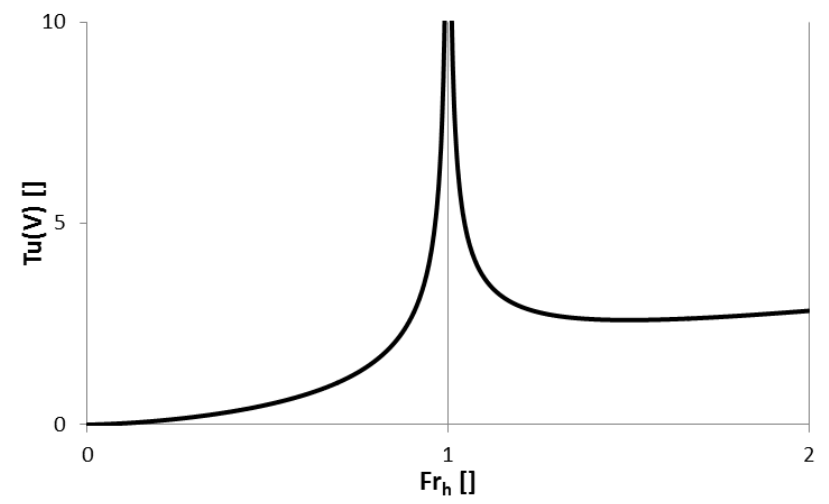

Figure 12 the Tuck number $\mathrm{Tu}(\mathrm{V})$ in the sub $\left(\mathrm{Fr}_{\mathrm{h}}<1\right)$ and super critical $\left(\mathrm{Fr}_{\mathrm{h}}>1\right)$ speed region

The Tuck number $\mathrm{Tu}(\mathrm{V})$ does not take into account the lateral restrictions of the fairway. However, these restrictions will decrease the critical speed. The critical velocity decreases 
in confined waters and will be smaller than $\sqrt{\text { gh }}$. In (Schijf 1949) the critical velocity $V_{\text {crit }}$ is calculated taking into account the blockage $\mathrm{m}$. The blockage is defined as the ratio between the midship area $\mathrm{A}_{\mathrm{M}}$ and the cross section area $\Omega$.

In infinitely wide cross sections the blockage factor tends to zero and for this reason the bathymetry at a lateral distance $\mathrm{y}_{\text {infl }}$ and beyond located from the vessel is not taken into account:

$$
\Omega_{\text {lim }}=\int_{0}^{h} \int_{-y_{\text {infl }}}^{y_{\text {infl }}} d \Omega
$$

Now the blockage is:

$$
\boldsymbol{m}_{\text {lim }}=\frac{A_{M}}{\Omega_{\text {lim }}}=\frac{C_{M} \cdot B T}{\Omega_{\text {lim }}}
$$

A disadvantage of limiting the cross section to the influence width is that the minimal value for the blockage in shallow unrestricted waters is no longer zero but will have a minor value. The dimensionless critical speed $\mathrm{Fr}_{\text {crit }}$ according to (Schijf 1949) is calculated with the cross section within the influence width $\Omega_{\text {lim. }}$. As such, the critical speed $F_{\text {crit,lim }}$ is obtained:

$$
F r_{\text {crit }, \text { lim }}=\left(2 \sin \left(\frac{\operatorname{Arcsin}\left(1-m_{\text {lim }}\right)}{3}\right)\right)^{\frac{3}{2}}
$$

This dimensionless speed can be made dimensional by multiplying by $\sqrt{\mathrm{gh}_{\mathrm{avg}}}$. This water depth $\mathrm{h}_{\mathrm{avg}}$ is the ratio between the (limited) cross section area $\Omega$ (equation (12)) and the width on the free surface $\mathrm{W}_{0}$. The latter is the summation of the width on the free surface at the port and starboard side of the vessel (measured from the centre line of the vessel). Again both distances are limited to $\mathrm{y}_{\text {infll }}$.

$$
\boldsymbol{h}_{\text {avg }}=\frac{\Omega_{\text {lim }}}{W_{0}}
$$

Remark that the water depth $\mathrm{h}_{\text {avg }}$ in a canal section does not take the water depth under the vessel into account but the average over the entire cross section (within the limits defined by $\left.y_{\text {infl }}\right)$. Now the critical speed is:

$V_{\text {crit }}=\sqrt{g h_{\text {avg }}} F r_{\text {crit }, \text { lim }}=\sqrt{g h_{\text {avg }}}\left(2 \sin \left(\frac{\operatorname{Arcsin}\left(1-m_{\text {lim }}\right)}{3}\right)\right)^{\frac{3}{2}}$

The Tuck number is now adapted to $\mathrm{Tu}_{\mathrm{m}}$ causing a shift to the left of the vertical asymptote in Figure 12 , which is now located at the critical speed which takes into account the limited blockage as in equation (13):

$$
\boldsymbol{T} u_{m}(V)=\frac{\left(\frac{F r_{h}}{F r_{\text {crit lim }}}\right)^{2}}{\sqrt{1-\left(\frac{F r_{h}}{F r_{\text {crit }, \text { lim }}}\right)^{2}}}=\frac{\frac{h_{\text {avg }} V^{2}}{h_{\text {ship }} \text { crit }, \text { lim }^{2}}}{\sqrt{1-\frac{h_{\text {avg }} V^{2}}{h_{\text {shipV }}}}}
$$

The numerator of equation (17) can be written as:

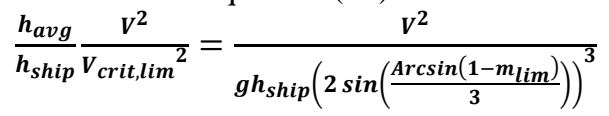

And as such the Tuck number equals:

$$
\boldsymbol{T} u_{m}(V)=\frac{\frac{V^{2}}{g h_{\text {ship }}\left(2 \sin \left(\frac{\operatorname{Arcsin}\left(1-m_{\text {lim }}\right)}{3}\right)\right)^{3}}}{\sqrt{\left.\left.1-\frac{V^{2}}{g h_{\text {ship }}\left(2 \operatorname { s i n } \left(\frac{A r c s i n}{}\left(1-m_{\text {lim }}\right)\right.\right.}\right)\right)^{3}}}
$$

A propeller generating (positive) thrust, at a positive rotational speed, accelerates the water flow passing the propeller disk and therefore increases the velocity of the water between bank and ship and thus decreases the pressure on that area of the hull. The influence of the propeller action on the lateral force will be modelled as a partial increase of the forward speed of the vessel $\left(\mathrm{V}_{\mathrm{eq}}\right)$ :

$$
\mathbf{V}_{\text {eq }}=\mathbf{V}+\xi_{\mathrm{VT}} \mathbf{V}_{\mathrm{T}}
$$

The coefficient $\xi_{\mathrm{VT}, \mathrm{A}}$ takes, for the lateral force at the aft perpendicular, a value between 0 and 1 . For the lateral force at the forward perpendicular this coefficient $\xi_{\mathrm{VT}, \mathrm{F}}$ is a much smaller value than $\xi_{\mathrm{VT}, \mathrm{A}}$ for the same ship. This is ascribed to the closer distance between the propeller and aft perpendicular than between the propeller and forward perpendicular. The ratio between the ship's length $\mathrm{L}_{\mathrm{pp}}$ and the propeller diameter (D) appears to be a relevant parameter; for ships with a large $\mathrm{L}_{\mathrm{pp}} / \mathrm{D}$ value, the influence of the propeller action on the lateral force at the forward perpendicular is even absent (Figure 13).

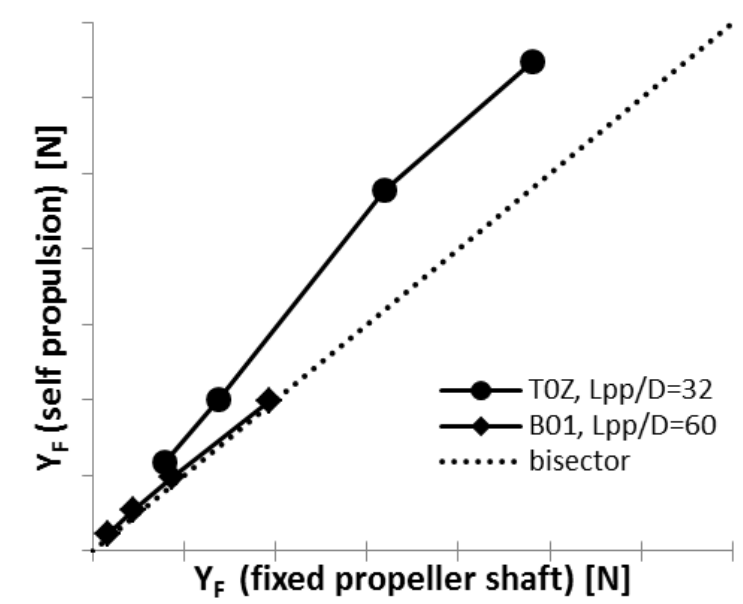

Figure 13 the lateral force at the forward perpendicular without an active propeller action $(0 \mathrm{rpm})$ plotted for the same test with active propeller action (according to selfpropulsion in open water). Abscissa and ordinate are intentionally left blank for reasons of confidentiality.

The thrust velocity $V_{T}$ is calculated based upon the thrust $T_{P}$ (as measured on the propeller shaft):

$$
\frac{T_{P}}{\frac{1}{2} \rho A_{0} V_{T}^{2}}=1
$$


When the ship model is towed in a towing tank with a forward speed and with propeller rate $0 \mathrm{rpm}$ the axial force as measured on the propeller shaft will take a small negative value. To be able to calculate negative values for $V_{T}$ the absolute value of $T_{P}$ is used under the root and the root is multiplied by the sign of the thrust $\left(\mathrm{V}_{\mathrm{T}}=0\right.$ when $\left.\mathrm{T}_{\mathrm{P}}=0\right)$ :

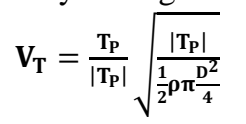

Only the thrust delivered by the propeller closest to the nearest bank is taken into account in case of a twin screw vessel.

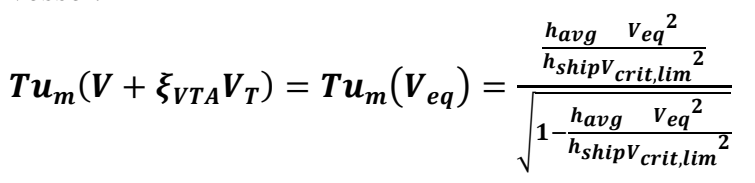
account:

The Tuck number $\mathrm{Tu}_{\mathrm{m}}\left(\mathrm{V}_{\mathrm{eq}}\right)$ from equation (23) takes into

- $\quad \mathrm{V}$ : the forward speed through the water of the vessel;

- $\mathrm{V}_{\mathrm{T}}$ : the propeller action;

- $\mathrm{m}_{\mathrm{lim}}$ : the dimensions of the fairway's cross section $\left(\Omega_{\mathrm{lim}}\right)$ and the midship area $\left(\mathrm{A}_{\mathrm{M}}\right)$.

In Figure 14 the lateral force at the aft perpendicular is plotted to the dimensionless $\mathrm{Tu}_{\mathrm{m}}\left(\mathrm{V}_{\mathrm{eq}}\right)$. A wide range of water depths, ship speeds and propeller actions are included.

$$
\begin{aligned}
Y_{A} & \propto T u_{m}\left(V_{e q}\right) \\
Y_{F} & \propto T u_{m}\left(V_{e q}\right)
\end{aligned}
$$

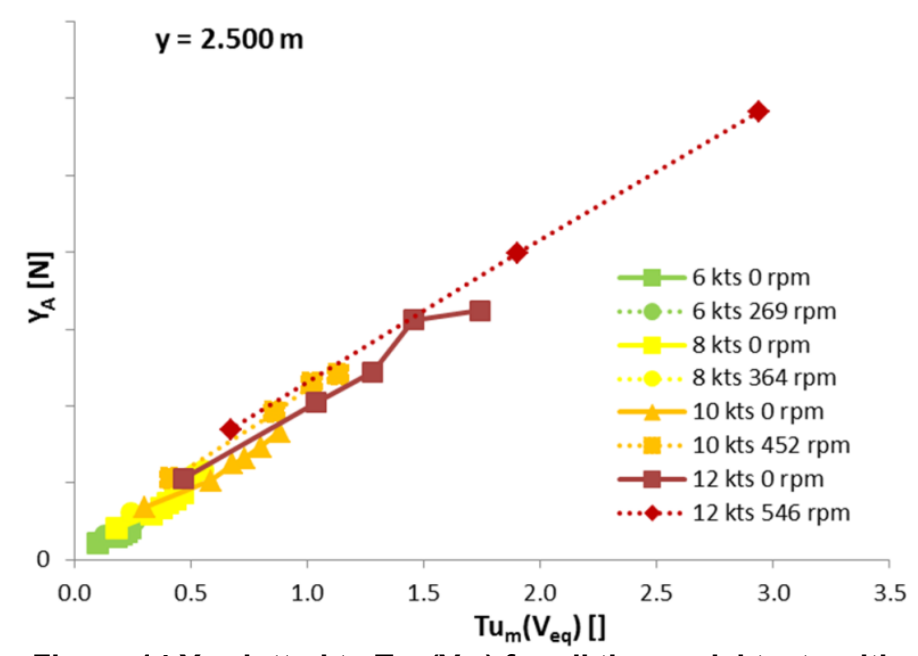

Figure $14 \mathrm{Y}_{\mathrm{A}}$ plotted to $\mathrm{Tu}_{\mathrm{m}}\left(\mathrm{V}_{\mathrm{eq}}\right)$ for all the model tests with A01 without influence of the boundary layer in cross section QY_0_7.00_0 at a lateral position $y=2.500 \mathrm{~m}$. Ordinate is intentionally left blank for reasons of confidentiality

\section{MATHEMATICAL MODEL}

The combination of equation (9) and equation (24) results in:

$$
Y_{A} \propto d 2 b^{-1} T u_{m}\left(V_{e q}\right)
$$

The right hand side (which is dimensionless) is multiplied by the displacement force $\Delta[\mathrm{N}]$ of the ship under consideration. To get an equation instead of a proportion the constant $\xi_{\rho}$ is added:

$$
Y_{A}=\xi_{\rho} \Delta d 2 b^{-1} T u_{m}\left(V_{e q}\right)
$$

Only four coefficients are used in the mathematical model for $\mathrm{Y}_{\mathrm{A}}$. This set of four coefficients is only valid for one displacement condition of one ship and within the boundaries of the mathematical model.

- $\xi_{\rho}[0,+\infty]$ copes with the overall proportionality of the model and the force $\mathrm{Y}_{\mathrm{A}}$

- $\boldsymbol{\xi}_{V T, \boldsymbol{A}}[0,1]$ part of the thrust velocity $\mathrm{V}_{\mathrm{T}}$ to be added to the forward speed $\mathrm{V}$ to create the equivalent velocity $\mathrm{V}_{\text {eq }}$.

- $\xi_{y}[0,+\infty]$ the lateral decrease of the weight factor $w$ for the water particles away from the ship

- $\xi_{z}[0,+\infty]$ the vertical decrease of the weight factor w towards the bottom

The lateral force at the forward perpendicular induced by bank effects can be mathematically modelled as:

$Y_{F}=\xi_{\rho} \Delta d 2 b^{-1} T u_{m}\left(V_{e q}\right) f\left(h, T, F r, \xi_{h T} \xi_{h}\right)$

This formulation consists of six independent coefficients $\left(\xi_{\rho} \xi_{y} \xi_{z} \xi_{V T, F} \xi_{h T} \xi_{h}\right)$ of which two $\left(\xi_{y} \xi_{z}\right)$ can be taken identical with the mathematical model for $\mathrm{Y}_{\mathrm{A}}$ for the same ship at the same initial draft condition.

The water depth has an impact on the force $\mathrm{Y}_{\mathrm{F}}$. In very deep water there is always attraction towards the closest bank while in very shallow water a repulsion force away from the closest bank is consistent. In between, the force can have both directions and therefore a relative water depth and Froude number dependent function is introduced $f\left(h, T, F r, \xi_{h T} \xi_{h}\right)$. A positive value indicates an attraction force, a negative value a repulsion away from the closest bank.

At the aft perpendicular the lateral force $\mathrm{Y}_{\mathrm{A}}$ is for all water depths an attraction force directed towards the closest bank. The attraction force at the aft perpendicular $\mathrm{Y}_{\mathrm{A}}$ is, in deeper water, larger than the attraction force at the forward perpendicular $\mathrm{Y}_{\mathrm{F}}$. The combination of these two forces results in an overall attraction towards the closest bank in combination with a bow out moment away from the closest bank (Figure 3). In very shallow water the magnitude of the repulsion force at the forward perpendicular is sometimes larger than the attraction force at the aft perpendicular. Both forces will then result in an overall repulsion force away from the closest bank in combination with a (large) bow away moment. 


\section{CONCLUSIONS}

Flanders Hydraulics Research carried out an enormous amount (+14 000) of model tests dedicated to bank effects in their shallow water towing tank. These model tests are the foundation of the present mathematical model for bank effects.

Only the hydrodynamic actions in the horizontal plane (parallel to the free surface) and directed perpendicular to the ship are considered in this paper. These forces are commonly split in a lateral force $\mathrm{Y}_{\mathrm{BANK}}$, and a moment $\mathrm{N}_{\mathrm{BANK}}$ around the vertical axis. The present mathematical model, however, splits the bank effects of the horizontal plane in:

- The lateral force at the forward perpendicular $Y_{F}$

- The lateral force at the aft perpendicular $\mathrm{Y}_{\mathrm{A}}$

The magnitude of the lateral force at the forward perpendicular $Y_{F}$, either an attraction or a repulsion force, will increase with the forward speed of the ship, or when the ship sails closer to the bank, or in a more confined cross section (with a larger blockage ratio). The propeller actions (located close to the aft perpendicular) have only a minor influence on this lateral force at the forward perpendicular.

The faster the ship sails, the larger the attraction force at the aft perpendicular will be. This attraction force will also increase when the propeller is loaded more. A more narrow distance between ship and bank or keel and bottom will also result in a larger attraction $\mathrm{Y}_{\mathrm{A}}$. The same is true for a larger blockage ratio (more confined waters).

The loading of the propeller (thrust $\mathrm{T}_{\mathrm{P}}$ ) is first transformed into a velocity $\mathrm{V}_{\mathrm{T}}$ and then this velocity is partially $\left(\xi_{\mathrm{VT}, \mathrm{A}}, \xi_{\mathrm{VT}, \mathrm{F}}\right)$ added to the forward velocity of the ship $\mathrm{V}$ to result in the equivalent velocity $\mathrm{V}_{\text {eq }}$. The equivalent velocity is used as input to calculate the Tuck number. Through the limited blockage ratio $\left(\mathrm{m}_{\text {lim }}\right)$ this Tuck number $\mathrm{Tu}_{\mathrm{m}}$ takes into account the decreased critical speed $\left(\mathrm{Fr}_{\text {crit,lim }}\right)$ in more confined waters. Both lateral forces $\mathrm{Y}_{\mathrm{F}}$ and $\mathrm{Y}_{\mathrm{A}}$ are proportional to the Tuck number calculated with equivalent forward speed $\mathrm{Tu}_{\mathrm{m}}\left(\mathrm{V}_{\mathrm{eq}}\right)$.

The closer a ship sails to a bank, the larger the bank effects will be. A value indicating the distance between a ship and any random bank geometry which takes into account all the nuances of that geometry is needed. Therefore the weight distribution is introduced. The weight factor (w) is a value between 0 and 1 to indicate the impact of the relative position on the bank effect. The largest value for $\mathrm{w}(=1)$ is located at the intersection of the (undisturbed) free surface and the $\mathrm{X}-\mathrm{Z}$ plane in the ship bound coordinate system. The weight factor is a value exponentially decreasing the further the point of consideration is away from the location of that peak point. The 'weight' $\chi$ is the integral over the area under consideration and is always a positive value.

The distance between ship and bank is mathematically modelled with the parameter $\mathrm{d} 2 \mathrm{~b}$. The inverse of this value $\left(\mathrm{d} 2 \mathrm{~b}^{-1}\right)$ is zero when sailing on the centre line of a symmetric cross section and its magnitude can become very large when sailing very close to a bank. Both lateral forces $\mathrm{Y}_{\mathrm{F}}$ and $\mathrm{Y}_{\mathrm{A}}$ are proportional to the inverse of $\mathrm{d} 2 \mathrm{~b}$.

\section{ACKNOWLEDGEMENTS}

This research project was funded by the Flemish Government, Department Mobility and Public Works, and the model tests were executed in 2007 and 2010 by Flanders Hydraulics Research (Antwerp, Belgium). The presented research is executed in the frame of the Knowledge Centre Ship Manoeuvring in Shallow and Confined Water, a cooperation between Flanders Hydraulics Research and the Maritime Technology Division of Ghent University.

\section{REFERENCES}

Van Kerkhove, G., Vantorre, M. \& Delefortrie, G., 2009. Advanced Model Testing Techniques for Ship Behaviour in Shallow and Confined Water. Proceedings of The First International Conference on Advanced Model Measurement Technology for the EU Maritime Industry, p.29.

Lataire, E. \& Vantorre, M., 2008. Ship-Bank Interaction Induced by Irregular Bank Geometries. In 27th Symposium on Naval Hydrodynamics. Seoul, Korea, pp. 5-10.

Lataire, E., Vantorre, M. \& Eloot, K., 2009. Systematic Model Tests on Ship-Bank Interaction Effects. International Conference on Ship Manoeuvring in Shallow and Confined Water: Bank Effects, pp.9-22.

Norrbin, N.H., 1974. Bank Effects on a Ship Moving through a Short Dredged Channel. In R. D. Cooper \& S. W. Doroff, eds. 10th ONR. Office of Naval Research, pp. 71-88.

Schijf, J.B., 1949. Protection of Embankments and Bed in Inland and Maritime Waters, and in Overflow or Weirs. In XVII International Navigation Congress, Lisbon, Section I. pp. 61-78.

Stern, F. \& Agdrup, K., 2008. SIMMAN 2008 Workshop on Verification and Validation of Ship Maneuvering Simulation Methods. In Workshop Proceedings. p. 2008.

Tuck, E.O., 1966. Shallow-Water Flows Past Slender Bodies. Journal of Fluid Mechanics, 26, pp.81-95.

Venables, W., Smith, D. \& Team, R.D.C., 2002. An introduction to R., 0 .

Zou, L. \& Larsson, L., 2013. Computational Fluid Dynamics (CFD) Prediction of Bank Effects Including Verification and Validation. Journal of Marine Science and Technology, 18, pp.310-323. 